\title{
Oilfield Performance Prediction using Integrated Modeling and Simulation (MBAL) Suite
}

\section{Authors: Julius Wosowei (Researcher) ${ }^{1}$; Prof. Chandrasekar Shastry (Guide) ${ }^{2}$}

\author{
Affiliation: Computer Science and Engineering, Jain (Deemed to be) University) ${ }^{1}$; Dean, PG \\ Studies, FET, Jain (Deemed to be) University ${ }^{2}$ \\ E-mail: julius.wosowei@gmail.com ${ }^{1}$; cshastry2@gmail.com ${ }^{2}$
}

\section{DOI:10.26821/IJSHRE.9.8.2021.9806}

\begin{abstract}
The Material Balance (MBAL) software is a component of the Petroleum Experts' Integrated production modeling (IPM) tool kit and it is used for the development of the Reservoir model. It allows and improves the understanding of the field behavior in terms of the field performance, production, flow behavior and optimization of the field at any given time of the lifespan of the field. The paper demonstrates reservoir performance prediction using dynamic $M B A L$ and predictive material balance method after proper history matching of the models and validated with appropriate data. The objective of the research is to set up a basic Reservoir Model with the PVT analysis, production and tank data. The paper further shows history matching by matching Original Hydrocarbon in place (OHIP) and Aquifer size and plots with required parameters against simulated results and prediction of future hydrocarbon production.
\end{abstract}

Keywords: Integrated production modeling, Oilfield performance, Reservoir simulation, MBAL.

\section{INTRODUCTION}

The real oilfield consists of the Reservoirs, Wells, the Production gathering system, the Distribution Network and the Injection Network. The Production gathering system receives the fluid from the functional producing wells and delivers to the flow station or gathering station for separation of fluids/ processing into its constituent components of Oil, Water and Gas. The Injection network inject fluid (water or gas) into the reservoir to enhance further recovery. The philosophy of the design of any Oilfield facility remains the same as the optimization of hydrocarbon production with minimal cost over the long run period of the investment outlay, though the layout of the production assets in the fields differ. Integrated Oilfield design implies that producing facility and the gathering system including the distribution pipeline network form a single total integrated system [1]. Integrated Oil production design covers an entire span of production activities ranging from the sub-surface structure, which comprises the drainage area, wells and wellhead assembly and surface facilities. The optimization models of the integrated system comprise of several component models including the Reservoir model, Choke model, Gathering 
Volume 9 Issue 8 August 2021

model and Economic model. Others are Pipeline model, Wellhead model, Thermodynamic model and the Integrated model. Economic goals however govern the objective function.

The Petroleum Experts' (PETEXs), Integrated Production Modeling (IPM) suite comprising of Pressure, Volume and Temperature Package (PVTP), the Material Balance software (MBAL), the Production and System Performance Analysis Software (PROSPER) and the General Application Package (GAP) suite provides an efficient multidisciplinary understanding of the complete production systems. The Integrated model is made up of the reservoirs and Wells (Subsurface) and the Surface facilities. The IPM provides an integrated analysis on all components leading to an effective product development, forecasting, surveillance and production network optimization. The MBAL suite is utilized to model the Reservoir components and PROSPER models the Well component while GAP tools model the Surface facilities [2]. IPM can be depicted as:

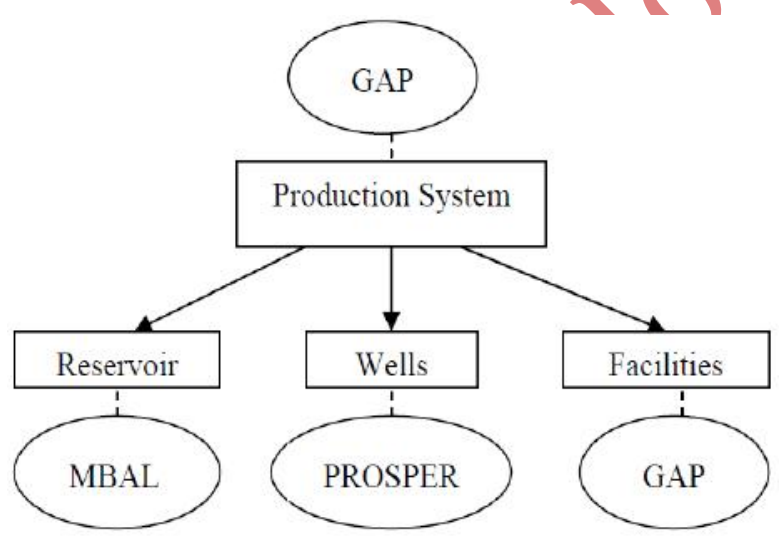

Fig.1 Production System Modeling

\section{RELATED WORK}

Emmanuel et al [3] developed a multi-Tank model to evaluate future well performance in reservoir using Material Balance (MBAL). This was in contrast to single tank model and achieved a better calibration and forecast of future opportunities. The methodology improved brownfield production forecast without requiring 3D dynamic models. The work was presented at the society of Petroleum Engineers (SPE) Nigeria annual international Conference and exhibition held in Lagos, Nigeria, 4-6 August 2015.

MR Woodman, J.Rodriguez, KC Wade and NJ Sanisatli [4] developed a Production and Facilities modeling and optimization technology. The work utilized a Physics-based prediction model coupled with mathematical optimization to model a complex Asset comprising separator, Riser, manifold, Well and Wellhead.

R.R.Kumar and H.K.B.Mahmud [5] focused on the optimization of a gas well with complex behavior by introducing condensate near wellbore. The work implemented sensitivity analysis in PROSPER and

Mónte Carlo resulting improved production

\section{METHODOLOGY}

3.1 Development of the Reservoir Model (MBAL) Material Balance (MBAL) is based on the law of mass conservation and is derived as a volume balance that compares observed cumulative volume of production with reservoir fluid expansion due to drop in finite pressure. The MBAL software defines the hydrocarbon volume and drive mechanisms that allows reliable production forecast through simulation [6]. This is expressed as:

Mass of fluid originally in place $=$ Fluids produced $+$

Remaining Fluids in place.

Production=STOIIP*Unit Expansion + water Influx 
Volume 9 Issue 8 August 2021

The material balance equation was modified by Havlena and Odeh to derive a straight-line equation [7] as follows:

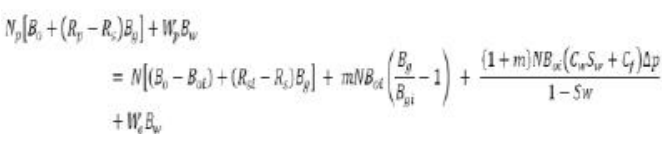

The reduced form is

$$
\begin{aligned}
& F=N_{p}\left[B_{0}+\left(R_{p}-R_{s}\right) B_{g}\right]+W_{p} B_{W W}(r b) \\
& E_{0}=\left[\left(B_{0}-B_{0 i}\right)+\left(R_{s i}-R_{s}\right) B_{g}\right](r b / s t b) \\
& E_{g}=B_{0 i}\left(\frac{B_{g}}{B_{g i}}-1\right) \quad(r b / s t b) \\
& E_{f W}=(1+m) B_{0 i}\left(\frac{C_{W} S_{W c}+C_{f}}{1-S_{W c}}\right) \Delta p(r b / s t b)
\end{aligned}
$$

The simplified form can be stated as

$$
F=N\left(E_{0}+E_{f W}+E_{g}\right)+W_{e} B_{W}
$$

Therefore, taking a plot of $\left(F / E_{0}+E_{f w}+E_{g}\right) V s$ $\mathrm{W}_{\mathrm{e}} \mathrm{B}_{\mathrm{w}} /\left(\mathrm{E}_{0+} \mathrm{E}_{\mathrm{fw}+} \mathrm{E}_{\mathrm{g}}\right)$ gives a linear relationship with intercept $\left(\mathrm{W}_{\mathrm{e}} \mathrm{B}_{\mathrm{w}}\right)$ estimating the original Hydrocarbon in place(OHIP)with a unit slope meaning a reservoir model is achieyed and the aquifer is identified. A situation where this does not exist implies, the deviation is a dynamic mechanism and further tunning of parameters is required to obtain linearity and presence of corrupted data in the analysis. It is important to note that MBAL does not account for reservoir geometry, Well orientation and formation geology and its analysis requires the average pressure and cumulative gas production.

The PVT data is one of the critical elements in the design of the Reservoir model. The crude composition differs from one region to another and research works carried out few dcades ago indicates the following Black Oil PVT Correlation coefficient[8].

\subsection{Standing Type Model}

The Standing correlation predicted bubble point pressure using readily available field data from 105 experimentally measured PVT from California, USA. The parameter used are: Bubble point pressure(Psi), solution gas-oil ratio(scf/stb), Gas Specific Gravity $\left(\mathrm{lb} / \mathrm{ft}^{3}\right)$, Oil Relative Density $\left({ }^{0} \mathrm{API}\right)$, and the Reservoir Temperature $\left({ }^{0} \mathrm{~F}\right)$. The Original Standing equation is stated as shown:

$$
P b=a_{1}\left[\left(\frac{R s}{\gamma_{g}}\right)^{a 2} 10^{X}-a_{5}\right], X=\left[a_{3} T-a_{4} \gamma_{0 A P I}\right]
$$

$$
\text { where }\left[a_{1}=18.2, a_{2}=0.83, a_{3}=0.00091, a_{4}=0.0125, a_{5}=1.4\right] \text {. }
$$

Other variants of the Standing correlation are:

Vazquez and Beggs:

$$
\mathrm{Pb}=\left[a_{1}\left(\frac{R_{s}}{\gamma_{g}}\right) 10^{X}\right]^{a_{2}}, X=\left[-a_{3} \frac{\gamma_{\text {OAPl }}}{(T+460)}\right]
$$

\section{(2)}

For $\mathrm{API}>30 \mathrm{a} 1=56.06, \mathrm{a} 2=0.84246, \mathrm{a} 3=10.393$
Petrosky and Farshad

$$
\begin{gathered}
P b=a_{1}\left[\left(\frac{R s^{2}}{\gamma_{8}^{33^{3}}}\right) 10^{X}-a_{4}\right], X=\left[a_{5} T^{a_{6}}-a_{7} \gamma_{0 A P I}{ }^{a_{8}}\right] \\
a_{1}=112.727, \mathrm{a}_{2}=0.5774, \mathrm{a}_{3}=0.8439, \mathrm{a}_{4}=12.34, \mathrm{a}_{5}=4.561 \times 10^{-5}, \mathrm{a}_{6}= \\
1.3911, \mathrm{a}_{7}=7.916 \times 10^{-4}, \mathrm{a}_{8}=1.541
\end{gathered}
$$

Farshad et al

$$
\begin{gathered}
P b=a_{1}\left[\left(\frac{R_{s}}{\gamma_{8}}\right)^{a_{2}} 10^{X}\right], X=\left[a_{3} T-a_{4} \gamma_{0 A P I}\right] \\
a_{1}=33.22, a_{2}=0.8283, a_{3}=0.000037, a_{4}=0.0142
\end{gathered}
$$

Didoruk and Chrismas

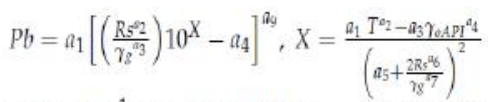

$\mathrm{a}_{1}=1.42828 \times 10^{-1}, \mathrm{a}_{2}=28445918, \mathrm{a}_{3}=-6.74896 \times 10^{-4}, \mathrm{a}_{4}=$ $1.2252264, \mathrm{a}_{5}=0.03338, \mathrm{a}_{6}=-0.272945, \mathrm{a}_{7}=-0.084226, \mathrm{a}_{8}=1.869979, \mathrm{a}_{9}$ (5) $=1.221486, \mathrm{a} 10=1.370508, \mathrm{a}_{11}=0.011688308$

\section{GOR Correlation}

The Gas-Oil-Ratio(GOR) correlation can be calculated by solving the bubble point pressure correlation for $\mathrm{R}_{\mathrm{s}}$ when our Standing's correlation is re-arranged and presented as: 
Volume 9 Issue 8 August 2021

$$
P_{h}=18.2(1-1,4)
$$

6)

Where

$$
A=\left(\frac{R_{s b}}{\gamma_{g}}\right)^{0.83} \times 10^{(0.000991 T-0.0125 .4 P I)}
$$

(7)

Therefore solving equations 6 and $7, \mathrm{R}_{\mathrm{s}}$ can be derived as

$$
\left.R_{g}=\gamma_{g}\left[10^{x}\left(\frac{P}{18.2}+1.4\right)\right]\right]^{1.21148}
$$

(8)

Where

$$
x=0.0125 \mathrm{API}-0.00091 \mathrm{~T}
$$

(9)

Moreso, the Standing 1947 California crude, Standing constructed a graphical Correlation of Oil Formation Volume Factor(Oil FVF) with an average error of $1.2 \%$ and in 1981 expressed it as:

(10)

$$
B_{0}=0.972+0.000147\left[R_{s}\left(\frac{y_{g}}{y_{0}}\right)^{0.5}+1.25 T\right]^{1.175}
$$

Thus, these Standing's correlations are valid for oil with trace composition of non hydrocarbon components.

\subsection{Input Parameters}

The MBAL input comprises the PVT data, tank data data, History matched Aquifer properties, relative permeability data, Production data(History) and

reservoir thickness. The Input parameters are as summarised below in table 1(PVT Data), table 2(Tank Data), table 3(Relative permeability) and table 4 shows Reservoir Data.
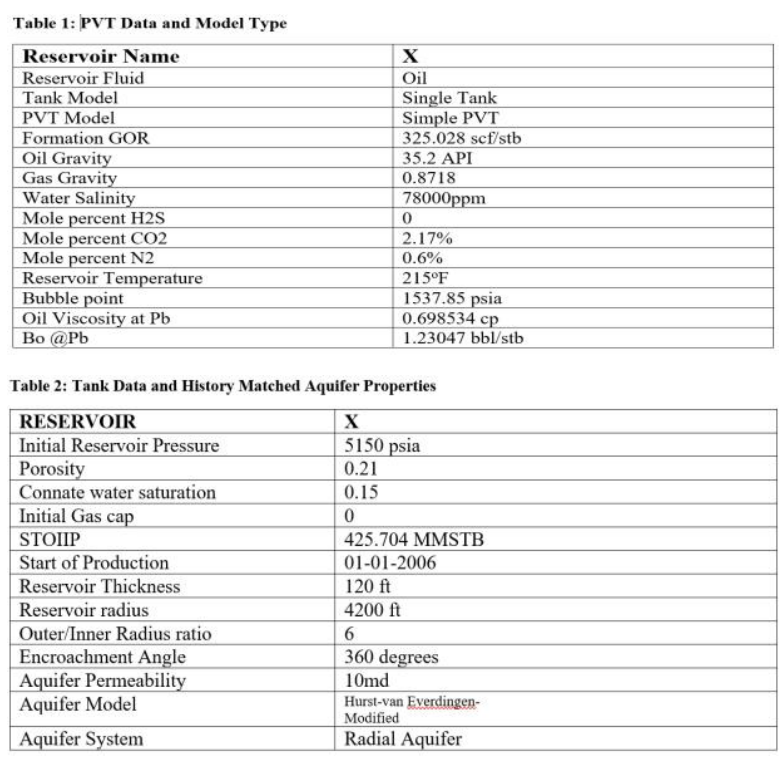

Table 3: Relative permeability $\mathrm{X}$

\begin{tabular}{|l|l|l|l|}
\hline & $\begin{array}{l}\text { Residual } \\
\text { Saturation }\end{array}$ & End Point & Exponent \\
\hline Krw & 0.15 & 0.676301 & 0.527657 \\
\hline Kro & 0.15 & 0.8 & 0.710008 \\
\hline Krg & 0.01 & 0.9 & 1 \\
\hline
\end{tabular}

Table 4: RESERVOIR X

\begin{tabular}{|l|l|l|l|l|}
\hline $\begin{array}{l}\text { Time } \\
\text { (dd-mm-yyyy) }\end{array}$ & $\begin{array}{l}\text { Reservoir } \\
\text { pressure (psig) }\end{array}$ & $\begin{array}{l}\text { Cumulative Oil } \\
\text { Produced } \\
\text { (MMSTB) }\end{array}$ & $\begin{array}{l}\text { Cumulative } \\
\text { GOR (Scf/Stb) }\end{array}$ & $\begin{array}{l}\text { Cumulative } \\
\text { Water Produced } \\
\text { (MMSTB) }\end{array}$ \\
\hline $01-01-2006$ & 5150 & 0 & 0 & 0 \\
\hline $02-04-2006$ & 5092.89 & 0.4277 & 325.027 & 0.0121601 \\
\hline $01-05-2006$ & 5078.26 & 0.564 & 325.028 & 0.0200325 \\
\hline $31-07-2006$ & 5010.96 & 1.18744 & 325.029 & 0.0704627 \\
\hline $30-10-2006$ & 4956.73 & 1.81088 & 325.028 & 0.141712 \\
\hline $29-01-2007$ & 4910.14 & 2.43432 & 325.028 & 0.231005 \\
\hline $30-04-2007$ & 4868.96 & 3.05776 & 325.028 & 0.336346 \\
\hline $30-07-2007$ & 4831.86 & 3.68121 & 325.026 & 0.456274 \\
\hline $29-10-2007$ & 4797.98 & 4.30465 & 325.028 & 0.589664 \\
\hline $28-01-2008$ & 4766.79 & 4.92809 & 325.029 & 0.735621 \\
\hline $28-04-2008$ & 4737.84 & 5.55153 & 325.028 & 0.893424 \\
\hline $01-08-2008$ & 4709.46 & 6.20237 & 325.027 & 1.07008 \\
\hline $01-10-2008$ & 4681.16 & 6.6825 & 325.028 & 1.20747 \\
\hline
\end{tabular}

\subsection{Overview of Reservoir X}

Description: Reservoir $\mathrm{X}$ is an undersaturated oil reservoir with an initial pressure of 5150 psia, a temperature of $215^{\circ} \mathrm{F}$ and a bubble point pressure of 1537.85 psia. It contains crude oil with an API gravity of 35.2 and has an initial solution gas oil ratio of $352.028 \mathrm{scf} / \mathrm{stb}$. It has a thickness of about $120 \mathrm{ft}$ and an initial oil in place of about 425 MMSTB.

\section{RESULTS AND DISCUSSION}

\subsection{PVT matching:}


The available PVT data was matched using different Black Oil PVT Models, to select the model that provides the best match for the acquired data. From the analysis, the Glaso correlation was found to provide the best match for Bubble point, Solution Gas-Oil Ratio and Oil formation volume factor. The Petrosky et al. correlation also provided the best match for Oil viscosity, gas viscosity and gas formation volume factor. Below are plots of the different matched properties against pressure:

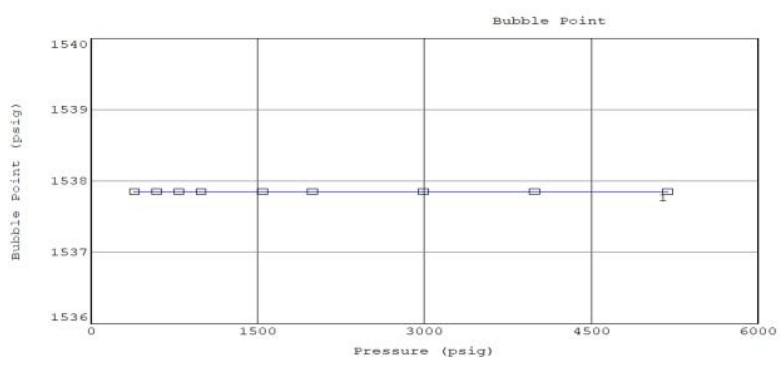

Fig.2: Bubble-point vs pressure

Shows the pressure at which the first bubble of the gas came out of the liquid oil solution. Bubblepoint determination is a crucial element in modeling and managing a reservoir. In this study, the Glaso-Correlation gave the best match for bubble-point with perfect horizontal line.

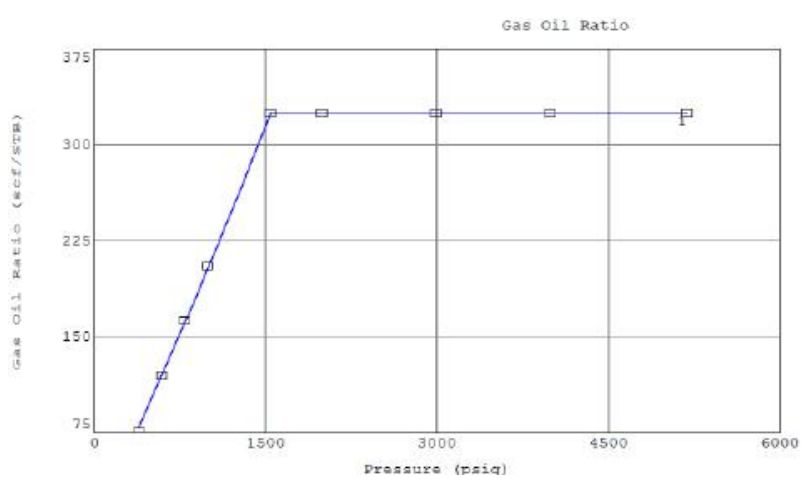

Fig. 3: GOR Vs Pressure.

This shows the surface gas dissolved in a stock tank at specific pressure and temperature. mathematically as $R_{\mathrm{S}}(\mathrm{SCF} / \mathrm{STB})$. Best plot for Gas-Oil-Ratio was given by Glaso-Correlation.

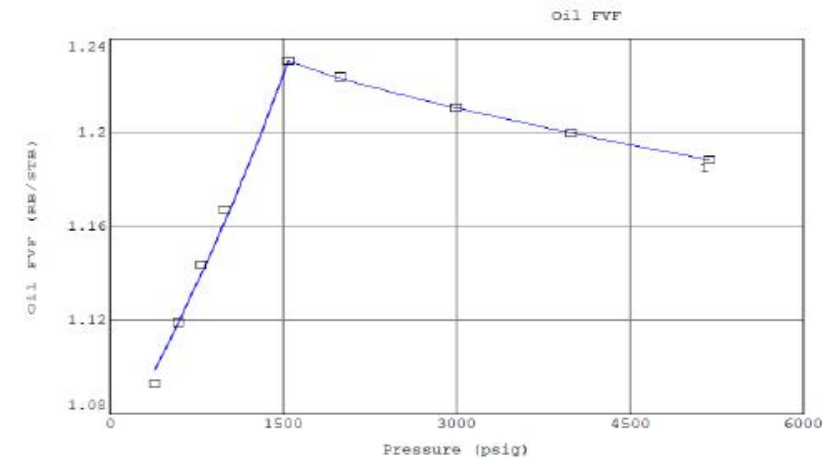

Fig. 4: Oil FVF Vs Pressure

Formation volume factor (FVF) vs pressure shows ratio of phase volume in relation to surface phase volume at standard condition when materials of reservoir are brought to the surface. Glasocorrelation shows best plot.

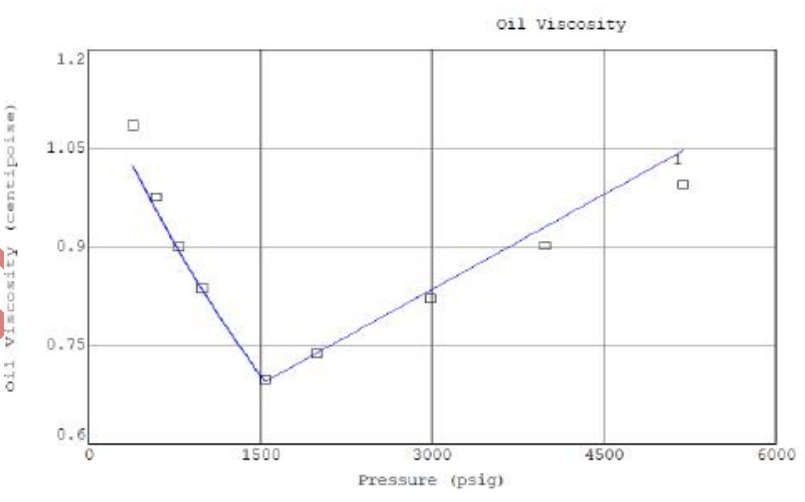

Fig. 5: Oil viscosity Vs pressure

Oil viscosity generally shows inverse relationship with pressure as oil viscosity increases with decrease in pressure at suturated condition due to disolved gases below bubble-point but viscosity increases with pressure due to liquid compression above bubble-point. However, Petrosky gave the best plot for Viscosity.

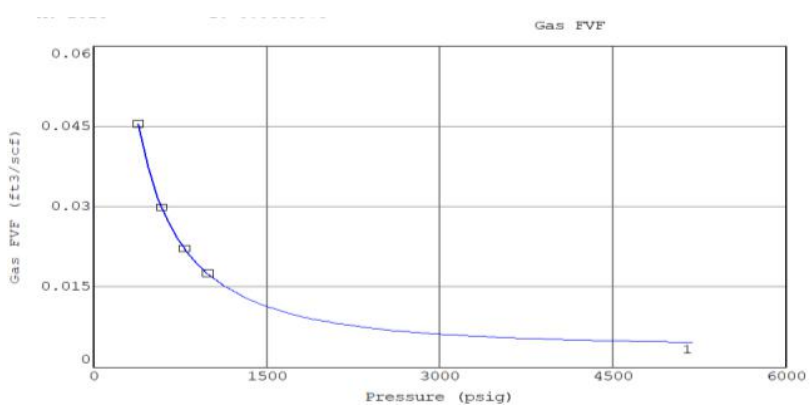

Fig. 6: Gas FVF Vs Pressure 
Volume 9 Issue 8 August 2021

The Glaso-Correlation provided the best match as shown.

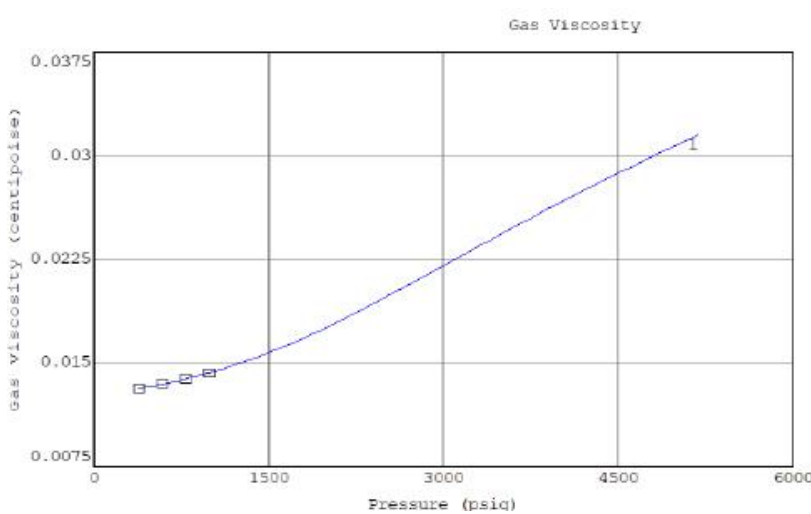

Fig. 7: Gas Viscosity Vs Pressure

Best plot was provided by Petrosky et al correlation.

\subsection{Production History Match}

\subsubsection{Without Aquifer:}

From the production history match without adding an aquifer, the following plots were obtained for the analytical and graphical methods as in figures 7 and 8 .

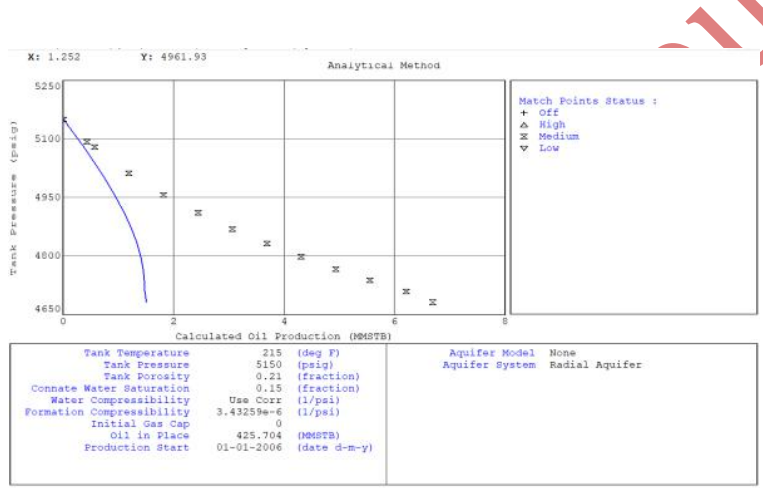

Fig. 8: Shows Analytical/Graphical plots without Aquifer.

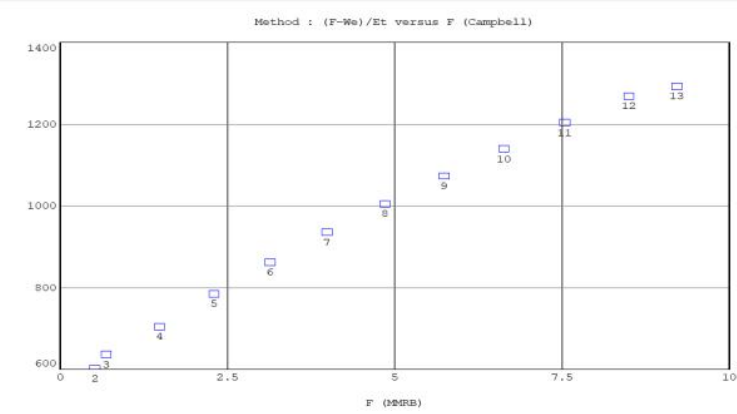

Fig. 9: Shows Cambell plot without Aquifer.
From the Campbell plot, the history data points do not lie on a straight line, showing that a good match has not be made and there may be the presence of an aquifer.

The Analytical plot also shows a mismatch between historical cumulative production and that derived from the model. It shows an underprediction of cumulative oil produced for a given pressure drop. For this reason, the presence of an aquifer is also suspected to be contributing to historical production.

\subsubsection{With Aquifer:}

A modified Van-Everdingen and Hurst aquifer model was set up to match historical production and the aquifer parameters with the highest uncertainties were regressed on to match historical data, all within well-defined boundaries that suit reasonable engineering and geological judgment. The parameters regressed on include: The encroachment angle, outer/inner radius, and aquifer permeability.

The following plots were generated after the regression on the different parameters:

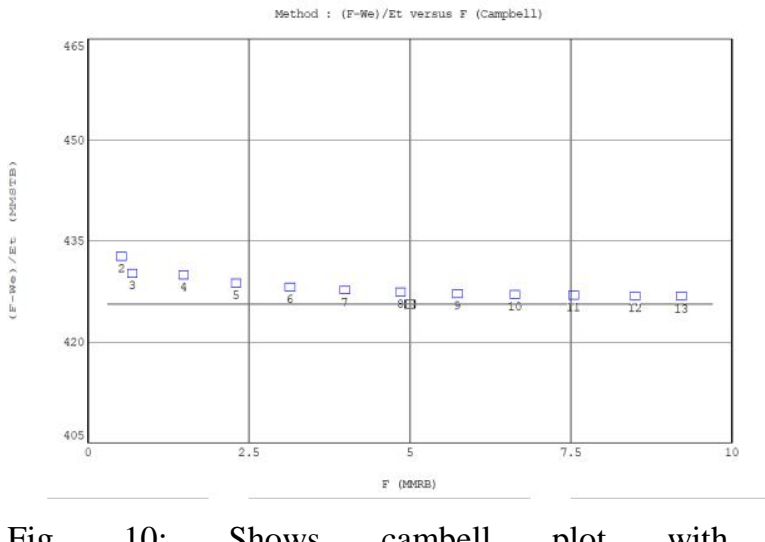

Fig. 10: Shows cambell plot with

Acquifer/Regression 
Volume 9 Issue 8 August 2021

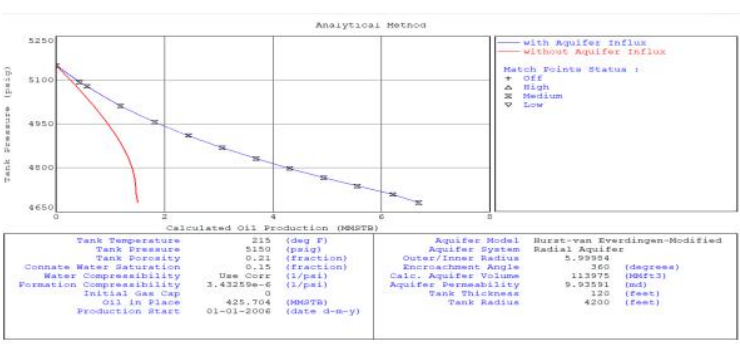

Fig. 11: Analytical plots with Acquifer

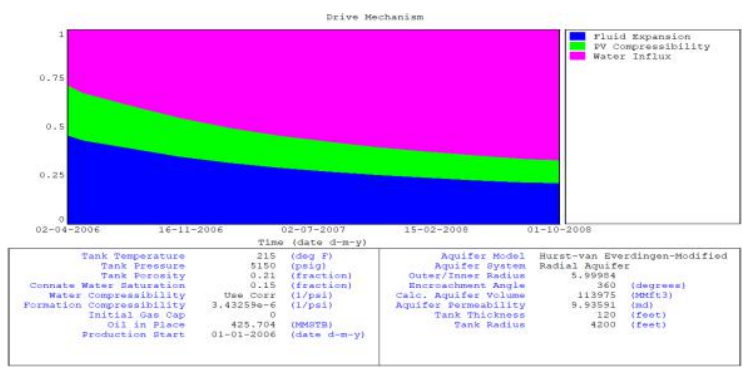

Fig, 12: Shows the Drive mechanism/Energy that drive the Reservoir

After defining an aquifer, and regressing on the uncertain parameters, it can now be seen that the Campbell plot now falls on straight line and the Analytical plot now follows the historical trend. The matched aquifer properties can be seen in the analytical plot above. The energy plot also shows that fluid expansion was initially the major drive mechanism, after which water drive became a major contributor to production.

With this, a good historical match has been made and predictions can now be carried out, after a good fractional flow model is obtained.

A pressure simulation was also carried out to determine the validity of the model, as shown below:

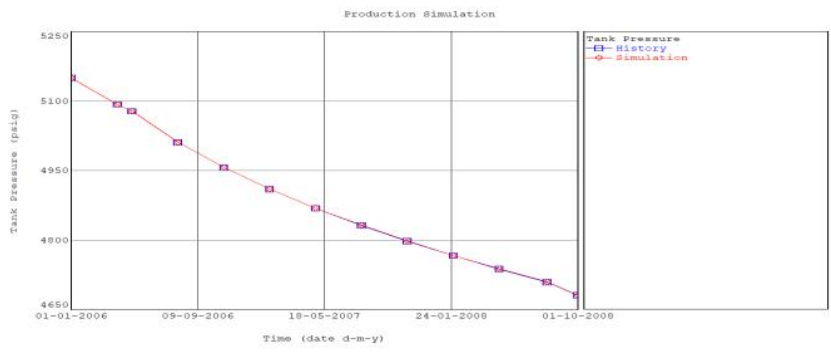

Fig. 13: Plot shows pressure simulation to check validity of model.
From the pressure simulation, we can see a good match between historical pressure and simulated pressures for reservoir $\mathrm{X}$.

Using the historical data, a good fractional flow match was obtained, as shown below:

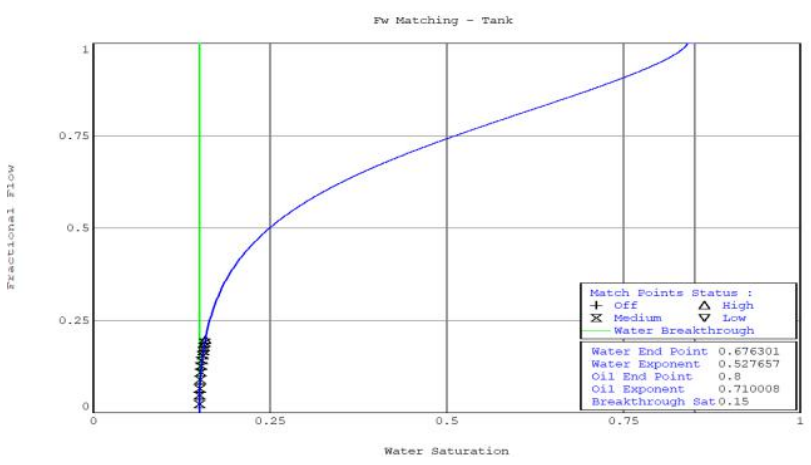

Fig. 14: Shows historical pressure and simulated pressures matching.

\section{CONCDUSION}

The material Balance (MBAL) is a sophisticated analytical tool to evaluate the volume of reservoir through historical production, data, results and plots obtained upon which the following conclusions have been drawn from the research work. Reliable PVT data is required to carry out reservoir volume evaluation in MBAL which initializes, calibrates and benchmarks the history matching. The energy plot shows fluid expansion as the major drive mechanism but thereafter, water drive became a major contributor to production. Further findings include the effect of salinity on water density and compressibility on water formation. The study also posited that reservoir analysis requires adequate understanding of the behaviors of oil, gas and water when flowing simultaneously through porous medium. Finally, it should be stated that, the reservoir model using MBAL suite does not take into account the geometry of the reservoir, position and well formation. 


\section{REFERENCES}

[1] Tuong-Van Nguyen, Yuri M. Barbosa, Julio A.M. da Silva, Silvio de Oliveira Junior, "A novel methodology for the design and optimization of oil and gas offshore platforms", Energy, Volume 185,2019, Pages 158-175, ISSN 03605442, https://doi.org/10.1016/j.energy.2019.06.164.

[2] Integrated Production modelling 2018, User manual, Edinburgh, Scotland, Petroleum Experts Ltd.

[3] Mogbolu, Emmanuel, Okereke, Onyedikachi, Okporiri, Cyril , Ukauku, Ikwan, Esharegharan, Ovokerhoyi, Taiwo, Isaac, and Ibianga Sukubo. "Using Material Balance (MBAL) Multi Tank Model to Evaluate Future Well Performance in Reservoirs with Distinct Geological Units." Paper presented at the SPE Nigeria Annual International Conference and Exhibition, Lagos, Nigeria, August 2015. doi: https://doi.org/10.2118/178484-MS

[4] Woodman, M., Rodriguez, J., Wade, K., \& Samsatli, N. (2017, November 7). New Integrated Technology for Full Production and/Facilities Modelling and Optimisation. Society of Petroleum Engineers. doi:10.2118/189263-MS

[5] Retnaruben Ratna Kumar and Hisham Khaled Ben Mahmud. "Production Optimization of Gas Wells Using MBAL" International Journal of Petroleum and Petrochemical Engineering (IJPPE) Volume 3, Issue 3, 2017, PP 90-100 ISSN 2454$7980 \quad$ (Online) DOI: http://dx.doi.org/10.20431/2454-7980.0303010

[6] MBAL Petroleum Experts 2018, User manual, MBAL Edinburgh, Scotland, Petroleum Experts Ltd.

[7] Ottah, D. G., Ikiensikimama, S. S., and S. A. Matemilola. "Aquifer Matching with Material Balance Using Particle Swarm Optimization Algorithm - PSO". Paper presented at the SPE
Nigeria Annual International Conference and Exhibition, Lagos, Nigeria, August 2015. DOI: https://doi.org/10.2118/178319-MS

[8] S. Alatefi and A. M. Almeshal, "A New Model for Estimation of Bubble Point Pressure Using a Bayesian Optimized Least Square Gradient Boosting Ensemble," Energies, vol. 14, no. 9, p. 2653, May 2021.

\section{Nomenclature:}

API - American Petroleum Institute

Bbl - Barrel

$\mathrm{Bg}$ - Gas formation volume factor

Bo - Oil formation volume factor

$\mathrm{Cp}$ - Centipoise

GOR - Gas Oil Ratio

$\mathrm{Krg}$ - Relative Permeability to Gas

Kro-Relative Permeability to Oil

Krw-Relative Permeability to Water

MD - Measured Depth

Md - milli Darcy

MMSTB - Million Stock Tank Barrel

MSTB - Thousand Stock Tank Barrel

$\mathrm{Pb}$ - Bubble point

Ppm - Parts Per Million

Psia - Pounds per square inch (Absolute)

Psig - Pounds per square inch (Gauge)

PVT - Pressure, Volume, Temperature

$\mathrm{R}_{\mathrm{p}}$-Producing Gas Oil Ratio

Scf - Standard Cubic Feet

SSSV - Subsurface Safety Valve

Stb - Stock Tank Barrel

STOIIP - Stock Tank Oil Initially in Place

TVD - True Vertical Depth 